CASE REPORT

\title{
Effective treatment of bone metastases from a neuroendocrine tumour of the pancreas with high activities of Indium-111-pentetreotide
}

\author{
Bernies van der Hiel, Marcel P M Stokkel, Arturo Chiti ${ }^{3}$, Giovanni Lucignani ${ }^{1}$, Emillio Bajetta ${ }^{2}$, Ernest K J Pauwels \\ and Emilio Bombardieri ${ }^{3}$ \\ Department of Nuclear Medicine, Leiden University Medical Center, PO Box 9600, 2300 RC Leiden, The Netherlands, ${ }^{1}$ Institute of Radiological Sciences, \\ A.O.L. Sacco, University of Milano, Italy, ${ }^{2}$ Unit of Oncology B, Istituto Nazionale per lo Studio e la Cura dei Tumori, Milano, Italy and \\ ${ }^{3}$ Nuclear Medicine, Istituto Nazionale per lo Studio e la Cura dei Tumori, Milano, Italy
}

(Correspondence should be addressed to B van der Hiel; Email: m.p.m.stokkel@lumc.nl)

\begin{abstract}
Objective: To evaluate therapy with high doses of ${ }^{111}$ Indium pentetreotide in a patient with bone metastases from a carcinoid of the pancreas.

Case report: A 55-year-old male presented in November 1990 with stomach ache with dorsal irradiation. Ultrasonography and computed tomography (CT-) scans of the abdomen revealed a tumour of the tail of the pancreas and liver metastases. Histological examination revealed a neuroendocrine tumour. Surgery and polychemotherapy were initiated and after seven cycles a tumour regression of 30\% was achieved. During follow-up multiple metastases were seen upon bone scintigraphy for which treatment with high doses Indium-111-octreotide was initiated.

Materials and methods: The patient underwent eight cycles, with one cycle every 5 weeks. Each treatment consisted of an i.v. injection of $6 \mathrm{GBq}$ Indium-111-pentetreotide. Comparing the results of the first and the last post-treatment scintigraphy, a regression of the number and intensity of uptake in the lesions was found. Bone scintigraphy showed a regression of the skeletal lesions as well, while $\mathrm{X}$-ray, CT-scan and chromogranin-A levels showed stable disease.

Conclusion: Results from the treatment of our patient indicate that the use of high dose radiolabelled somatostatin analogues could be of significant use, even in the case of bone metastases. To our knowledge, this is the first report describing therapeutic effects on bone metastases from a neuroendocrine tumour.
\end{abstract}

European Journal of Endocrinology 149 479-483

\section{Introduction}

Serotonin secreting tumours of the pancreas are very rare, comprising $<1 \%$ of all neuroendocrine tumours (1). Resection of local disease or of regional nodular metastatic disease cures some patients. However, the disease is usually diagnosed when the tumour is large and has already metastasised. At this stage, therapy is based on treating clinical symptoms caused by the increased hormone production and excretion $(1,2)$. Small series of liver transplantations have been reported but the long term results are unconvincing. In these studies, survival of patients with liver metastases from neuroendocrine tumours in which a liver transplantation has been performed varied from 2 to 61 months (3-6). Today, with the introduction of somatostatin analogues and particularly octreotide, most of the hormone-related symptoms can be controlled. Somatostatin analogues have also shown to be inhibitors of tumour growth, but data are conflicting (7). In more recent studies, tumour targeted radioactive treatment with Yttrium-90 or Indium-111 labelled analogues have been described $(8-11)$.

In this paper we report on a patient diagnosed with a carcinoid of the pancreas, who underwent radionuclide therapy with ${ }^{111}$ Indium pentetreotide to treat multiple bone metastases.

\section{Case report}

A 55-year-old male presented in November 1990 with stomach ache with dorsal irradiation. Ultrasonography (US) and computed tomography (CT-) scans of the abdomen showed a $5 \mathrm{~cm}$ lesion in the tail of the pancreas and enlargement of the spleen. Furthermore, multiple lesions were seen in the right lobe of the liver, the largest of which had a diameter of $10 \mathrm{~cm}$. 
Biopsy and histological examination of a specimen of one of the lesions revealed a neuroendocrine tumour with multiple liver metastases. The patient developed secondary diabetes as a result of the neoplasm invasion. Polychemotherapy was initiated (5-Fluorouracil, Farmarubicin, Detilin) and after seven cycles a tumour regression of $30 \%$ was achieved.

In July 1992 the patient underwent resection of the tail of the pancreas, a splenectomy and a resection of the retroperitoneal lymph nodes. Immunohistochemistry of the primary tumour showed a positive reaction to anti-5-phenylalanin, anti-polypeptide $\mathrm{P}$ and antichromogranin-A. The diagnoses of malignant carcinoid of the tail of the pancreas with secondary invasion to the spleen and metastases of the liver was made. Thereafter, the patient received a course of four cycles of chemotherapy according to Machover.

Four months after this intervention the patient was admitted to hospital for a transplantation of the liver and pancreatic islets. During the same surgical intervention the distal part of the stomach, the duodenum and the head of the pancreas were resected and a gastroentero anastomosis was constructed. The next day the liver and pancreatic islets were retransplanted because they were non-functioning due to acute rejection. The patient left the hospital in good health, but was admitted again 1 year later with acute hyperglycaemia. The transplanted pancreatic islets had not functioned and the patient had become completely insulin dependent. The patient remained symptom free for 19 months, after which he was admitted to hospital suffering from renal pain. A CT-scan of the abdomen showed a lesion $2 \mathrm{~cm}$ in diameter at the site of the left kidney. Renal aortic lymph nodes were resected and biopsies of the liver and left kidney were taken. Histologically the lesion appeared to be a retroperitoneal relapse of a carcinoid. The liver biopsy was taken in order to check its function, which appeared to be normal. Afterwards, the patient underwent local radiotherapy $(46 \mathrm{~Gy})$ on the left pararenal region.

In November 1995 bone scintigraphy was performed, which revealed a lesion in the right parietal bone of the skull. This lesion was not confirmed on X-ray or CTscan. One year later, the patient complained of abdominal pain, weight loss and difficulties with digestion and was admitted to hospital with malabsorbtion syndrome. Diagnostic examination (Barium X-ray of the gastrointestinal tract and gastroscopy) showed post-radiation stenosis of the gastroentero anastomoses and adherence of the middle part of the colon transversum to the anastomosis. The stenosis was resected with the attached part of the colon transversum and a new gastroentero anastomosis was constructed.

In March 1997, 5 months after the intervention, the patient was still symptom free. However, bone scintigraphy still showed a metastasis in the right parietal bone of the skull. Moreover, new lesions were found in the eleventh dorsal vertebra and the left anterior superior iliac wing. X-ray showed only a suspected metastasis at the left anterior superior iliac wing. No lesion was seen on the skull and the increased uptake in the eleventh vertebra was thought to be arthrosis. A CT-scan of the pelvis revealed a rounded hyperdense lesion at the left anterior superior iliac wing. Bone scintigraphy in July 1998 showed progressive disease. Lesions were seen in the skull, some ribs, at the cervical, dorsal, lumbar and sacral spine and in the left anterior superior iliac wing. A CT-scan of the abdomen and a diagnostic ${ }^{131}$ I-MIBG scan were negative. $\mathrm{X}$-ray showed a lesion at the eleventh dorsal vertebra which was now suspected to be a metastasis. The patient underwent whole body scintigraphy after the injection of $200 \mathrm{MBq}$ Indium-111-pentetreotide. This revealed more bone lesions than were seen upon bone scintigraphy, two node lesions in the epigastric region and one lesion in the transplanted liver. In December 1998, a CT-scan of the pelvis was made and a biopsy of the lesion on the left anterior superior iliac wing was taken. The biopsy revealed a metastasis from the neuroendocrine tumour.

To attempt to stabilise the disease, the patient was admitted in February 1999 to receive the first cycle therapy of ${ }^{111}$ In-pentetreotide therapy. Each treatment consisted of an i.v. injection of $6 \mathrm{GBq}{ }^{111} \mathrm{In}$-pentetreotide, diluted in $100 \mathrm{ml}$ of saline, over $30 \mathrm{~min}$. After the radionuclide infusion the patient was given $3000 \mathrm{ml}$ of saline with $20 \mathrm{mEq} \mathrm{KCl}$ to prevent renal damage from the radionuclide. The saline infusion was repeated for 3 days after the radionuclide administration. The therapeutic activity for each single treatment was obtained by labelling $50 \mu \mathrm{g}{ }^{111} \mathrm{In}$-pentetreotide with $6 \mathrm{GBq}{ }^{111}$ In-chloride. The total activity was obtained by labelling five vials of $10 \mu \mathrm{g}{ }^{111} \mathrm{In}-$ pentetreotide, each with $1.2 \mathrm{GBq}{ }^{111} \mathrm{In}$-chloride. The content of each vial was added to a saline vial in a total volume of $100 \mathrm{ml}$. Each vial was prepared according to the manufacturer's instructions for diagnostic Octreoscan, Mallinchrodt Inc., St Louis, MN, USA. Quality control measures were performed on each vial. In addition to the first cycle, the patient underwent seven cycles with one cycle every 5 weeks. Forty-eight hours after each cycle whole body and SPET scintigraphy were performed. Comparing the results of the post-treatment scintigraphy performed in February 1999 with the last scan performed in December 1999 , a regression of the number and uptake intensity of the lesions was found. Bone scan also showed a regression of the skeletal lesions while X-ray, CT-scan and chromogranin-A showed stable disease. Based on the higher sensitivity demonstrated by bone scan and Indium-111-octreotide scintigraphy in the previous imaging of the patient, we concluded the patient's disease was in regression (Fig. 1). The monitored haematological parameters did not show important changes during this treatment course. The lowest value of white blood cells was $4.1 \times 10^{3} / 1$ and of platelets was 

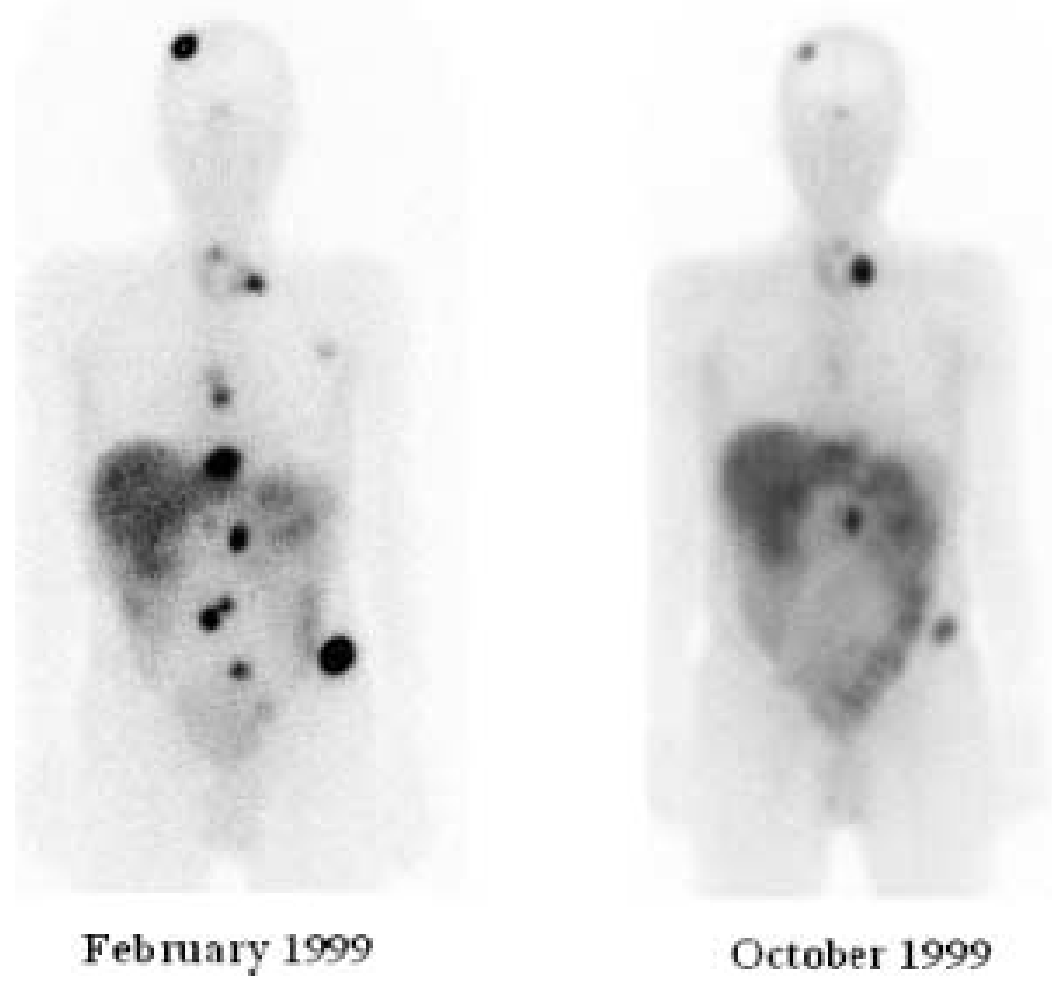

October 1999

Figure 1 Whole body scintigraphy of a patient treated with high activities of ${ }^{111}$ Indium-pentetreotide (anterior view) showing regression of metastases between the first and last treatment.

$107 \times 10^{3} / \mathrm{l}$. Haemoglobin levels ranged from 12.4 to $13.6 \mathrm{~g} / \mathrm{dl}$.

Approximately 1 month after the last cycle the patient had metastatic progression at the liver and abdominal lymph nodes as demonstrated by US and CT-scans and by an increase in chromogranin-A levels. Three months later, new skeletal metatastatic localisations were depicted by a bone scan, which was performed because of a reappearance of bone pain. Several weeks later, the patient developed severe hepatic failure and died.

\section{Discussion}

Carcinoid tumours are neuroendocrine tumours derived predominantly from enterochromaffin or Kulchitsky cells and like many neuroendocrine tumours are overexpressed with somatostatin receptors $(12,13)$. Somatostatin is a tetradecapeptide with the amino acids arranged in a cyclic fashion, configured by a cysteine-cysteine disulphide bridge. After binding to a somatostatin receptor, the complex is internalised and is again dissociated in the cell after which the somatostatin is transported into the nucleus (14-16).

Though some neuroendocrine gastrointestinal tumours can be treated successfully with surgery, neuroendocrine gastroenteropancreatic tumours usually present in a late stage when the disease has already metastasised $(17,18)$. In these cases, the basis for therapy is then not to cure, but to ameliorate clinical symptoms, reduce tumour growth and maintain and improve quality of life. Due to the development of somatostatin analogues, the clinical symptoms of the typical carcinoid, such as cutaneous flushing and diarrhoea can be successfully treated (19-21). These symptoms, caused by an overproduction of serotonin, have been reported in 70 to $90 \%$ of patients with metastatic carcinoid tumours (21).

Octreotide, an octapeptide that binds with high affinity to somatostatin type- 2 and -5 receptors, has like other somatostatin analogues a longer half-life $(1-2 \mathrm{~h})$ than native somatostatin $(1-2 \mathrm{~min})$ and it has demonstrated to be useful for neuroendocrine tumour treatment $(13,22)$. Somatostatin analogues labelled with a radioactive isotope are nowadays used to visualise neuroendocrine tumours. Somatostatin receptor scintigraphy can be considered the most important screening procedure for neuroendocrine gastrointestinal tumours (23). Iodine-123-labelled octreotide was the first somatostatin analogue used for this purpose. New developments have led to the introduction of pentetreotide, a pharmaceutical in which octreotide is chelated using diethylene triamine pentaacetic acid (DTPA) and labelled with Indium-111.

Many authors have demonstrated that scintigraphy with radiolabelled somatostatin analogues is an accurate method for diagnosing neuroendocrine tumours 
(12, 24-26). One of the first studies, by Lamberts et al., used scintigraphy with radiolabelled octreotide to successfully localise previously undetected primary or metastatic neuroendocrine tumours (27). The success of radiolabelled somatostatin analogues in visualising neuroendocrine tumours has led some authors to investigate whether higher doses may lead to the control of tumour growth. Indium-111 is a gamma ray emitter with two energy peaks at 171 and $245 \mathrm{KeV}$. As it decays by electron capture, in addition to the gamma rays and Auger electrons, it also emits conversion electrons. These electrons provide high energy within a short range. To be effective as a cytotoxic agent, Indium-111 must therefore be internalised within the cell. Several authors have demonstrated that radiolabelled somatostatin analogues, such as ${ }^{111}$ In-pentetreotide, are indeed internalised within the cell $(14,15,28)$. A limitation, however, is the rather low yield of conversion electrons that are emitted by Indium-111 per Bq, which is 0.050 per $\mathrm{Bq} \cdot \mathrm{s}$ and 0.083 per $\mathrm{Bq} \cdot \mathrm{s}$ for the $219 \mathrm{keV}$ and $145 \mathrm{keV}$ electrons, respectively. More recently, data have become available on the use of Yttrium-90 labelled somatostatin analogues (10, 11). Yttrium-90 is a pure beta-emitter, with a relative high energy of $935 \mathrm{keV}$ of the electrons emitted. The advantage it has over Indium-111 is that internalisation is not absolutely necessary for an optimal treatment effect. However, whole body scintigraphy after treatment to assess biodistribution and treatment effect is not possible due to the lack of photon emission. In addition, irradiation of normal surrounding tissue may also be more expected as a side-effect than with Indium-111 labelled analogues.

A few studies have been published that describe high dose treatment of ${ }^{111}$ In-pentetreotide in patients with neuroendocrine tumours (7, 9, 10, 29-31). Krenning et al. were the first to treat 21 patients with metastatic neuroendocrine tumours, where at least four doses of $6.6 \mathrm{GBq}{ }^{111} \mathrm{In}$-pentetreotide were given (30). In a study by McCarthy et al. (8), 35 patients entered a protocol that evaluated the effect of two doses $(6.6 \mathrm{GBq})$ a month apart. Öberg et al. treated five patients with successive $6 \mathrm{GBq}$ doses every 3 weeks (7). In all of these studies an improvement of Karnofsky Performance Status, biochemical and radiographic results were used as objective criteria for response. The overall response in patients with metastatic neuroendocrine tumours treated with a high dose $(6-19.6 \mathrm{GBq})$ ${ }^{111}$ In-pentetreotide is in the range of $60-65 \%$.

The patient we described was treated with high activities of ${ }^{111}$ In-pentetreotide. For a period of 11 months, a total of $48 \mathrm{GBq}{ }^{111}$ In-pentetreotide was given in eight doses (6 GBq per dose). Remarkably, during the course of treatment the patient showed no side effects and no toxicity was reported. Shortly after therapy, scintigraphic studies showed regressive disease, while X-ray and chromogranin-A levels were stable. No significant variations in the Karnofsky
Performance Status were reported during treatment over approximately 1 year.

Due to the availability of Indium-111 in our hospital we chose to use a single activity of $6 \mathrm{GBq}$. However, the optimal activity and the treatment scheduling is still a matter of debate. Today, surgery, medical treatment and chemotherapy are always considered in the therapeutic approach to neuroendocrine tumours of the gastroenteropancreatic tract. Results from the treatment of our patient and the above-mentioned studies support the theory that the use of high dose radiolabelled somatostatin analogues could be of significant use as well. To our knowledge, this is the first report describing therapeutic effects on bone metastases from a neuroendocrine tumour.

\section{Acknowledgements}

This paper has been partially supported by the AIRC grant (Italian Association for Cancer Research, Milano) and CNR grant (National Council for Research, Rome).

\section{References}

1 Mozell E, Stenzel P, Woltering EA, Rosch J \& O’Dorisio TM. Functional endocrine tumors of the pancreas: clinical presentation, diagnosis, and treatment. Current Problems in Surgery 199027 301-386.

2 Mao C, el Attar A, Domenico DR, Kim K \& Howard JM. Carcinoid tumors of the pancreas. Status report based on two cases and review of the world's literature. International Journal of Pancreatology 199823 153-164.

3 Arnold JC, O'Grady JG, Bird GL, Calne RY \& Williams R. Liver transplantation for primary and secondary hepatic apudomas. British Journal of Surgery 198976 248-249.

4 Loftus JP \& van Heerden JA. Surgical management of gastrointestinal carcinoid tumors. Advances in Surgery 199528 317-336.

5 Farmer DG, Shaked A, Colonna JO, Olthoff KM, Jurim O, Colquhoun $S$ et al. Radical resection combined with liver transplantation for foregut tumors. American Journal of Surgery 1993 $59806-812$.

6 Wenisch HJ, Markus BH, Herrmann GH, Usadel KH \& Encke A. [Multi-visceral upper abdominal resection and orthotopic liver transplantation - a surgical treatment concept for regionally metastatic tumors of the endocrine pancreas]. Zentralblatt fur Chirurgie $1992117334-342$.

7 Oberg K. Carcinoid tumors: molecular genetics, tumor biology, and update of diagnosis and treatment. Current Opinion in Oncology $20021438-45$.

8 McCarthy KE, Woltering EA, Espenan GD, Cronin M, Maloney TJ \& Anthony LB. In situ radiotherapy with 111In-pentetreotide: initial observations and future directions. Cancer Journal from Scientific America $1998494-102$.

9 McCarthy KE, Woltering EA \& Anthony LB. In situ radiotherapy with 111 In-pentetreotide. State of the art and perspectives. Quarterly Journal of Nuclear Medicine 200044 88-95.

10 Virgolini I, Traub T, Novotny C, Leimer M, Fuger B, Li SR et al. Experience with indium-111 and yttrium-90-labeled somatostatin analogs. Current Pharmaceutical Design 20028 1781-1807.

11 Virgolini I, Britton K, Buscombe J, Moncayo R, Paganelli G \& Riva P. In- and Y-DOTA-lanreotide: results and implications of 
the MAURITIUS trial. Seminars in Nuclear Medicine 200232 $148-155$.

12 Kwekkeboom DJ \& Krenning EP. Somatostatin receptor scintigraphy in patients with carcinoid tumors. World Journal of Surgery 199620 157-161.

13 Yamada Y, Kagimoto S, Kubota A, Yasuda K, Masuda K, Someya Y et al. Cloning, functional expression and pharmacological characterization of a fourth (hSSTR4) and a fifth (hSSTR5) human somatostatin receptor subtype. Biochemical and Biophysics Research Communications 1993195 844-852.

14 Hofland LJ, van Koetsveld PM, Waaijers M, Zuyderwijk J, Breeman WA \& Lamberts SW. Internalization of the radioiodinated somatostatin analog [125I-Tyr3]octreotide by mouse and human pituitary tumor cells: increase by unlabeled octreotide. Endocrinology 1995136 3698-3706.

15 Hofland LJ, van Koetsveld PM, Waaijers M \& Lamberts SW. Internalisation of isotope-coupled somatostatin analogues. Digestion 199657 (Suppl 1) 2-6.

16 Hofland LJ \& Lamberts SW. The pathophysiological consequences of somatostatin receptor internalization and resistance. Endocrine Reviews $20032428-47$.

17 Eriksson B, Arnberg H, Lindgren PG, Lorelius LE, Magnusson A, Lundqvist $\mathrm{G}$ et al. Neuroendocrine pancreatic tumours: clinical presentation, biochemical and histopathological findings in 84 patients. Journal of Internal Medicine $1990 \mathbf{2 2 8} 103-113$.

18 Norheim I, Oberg K, Theodorsson-Norheim E, Lindgren PG, Lundqvist G, Magnusson A et al. Malignant carcinoid tumors. An analysis of 103 patients with regard to tumor localization, hormone production, and survival. Annals of Surgery 1987206 115-125.

19 di Bartolomeo M, Bajetta E, Buzzoni R, Mariani L, Carnaghi C, Somma L et al. Clinical efficacy of octreotide in the treatment of metastatic neuroendocrine tumors. A study by the Italian Trials in Medical Oncology Group. Cancer 199677 402-408.

20 Ducreux M, Ruszniewski P, Chayvialle JA, Blumberg J, Cloarec D, Michel $\mathrm{H}$ et al. The antitumoral effect of the long-acting somatostatin analog lanreotide in neuroendocrine tumors. American Journal of Gastroenterology $2000953276-3281$.

21 Kvols LK, Moertel CG, O'Connell MJ, Schutt AJ, Rubin J \& Hahn RG. Treatment of the malignant carcinoid syndrome. Evaluation of a long-acting somatostatin analogue. New England Journal of Medicine $1986 \mathbf{3 1 5} 663-666$.

22 Kubota A, Yamada Y, Kagimoto S, Shimatsu A, Imamura M, Tsuda $\mathrm{K}$ et al. Identification of somatostatin receptor subtypes and an implication for the efficacy of somatostatin analogue SMS 201-995 in treatment of human endocrine tumors. Journal of Clinical Investigations 199493 1321-1325.

23 Seregni E, Chiti A \& Bombardieri E. Radionuclide imaging of neuroendocrine tumours: biological basis and diagnostic results. European Journal of Nuclear Medicine 199825 639-658.

24 Jamar F, Fiasse R, Leners N \& Pauwels S. Somatostatin receptor imaging with indium-111-pentetreotide in gastroenteropancreatic neuroendocrine tumors: safety, efficacy and impact on patient management. Journal of Nuclear Medicine $199536542-549$.

25 Kisker O, Bartsch D, Weinel RJ, Joseph K, Welcke UH, Zaraca F et al. The value of somatostatin-receptor scintigraphy in newly diagnosed endocrine gastroenteropancreatic tumors. Journal of American College of Surgeons $1997 \mathbf{1 8 4} 487-492$.

26 Perault C, Schvartz C, Wampach H, Liehn JC \& Delisle MJ. Thoracic and abdominal SPECT-CT image fusion without external markers in endocrine carcinomas. The Group of Thyroid Tumoral Pathology of Champagne-Ardenne. Journal of Nuclear Medicine 199738 1234-1242.

27 Lamberts SW, Bakker WH, Reubi JC \& Krenning EP. Somatostatinreceptor imaging in the localization of endocrine tumors. New England Journal of Medicine 1990323 1246-1249.

28 Andersson P, Forssell-Aronsson E, Johanson V, Wangberg B, Nilsson O, Fjalling $\mathrm{M}$ et al. Internalization of indium-111 into human neuroendocrine tumor cells after incubation with indium-111-DTPA-D-Phe1-octreotide. Journal of Nuclear Medicine $1996372002-2006$.

29 Espenan GD, Nelson JA, Fisher DR, Diaco DS, McCarthy KE, Anthony LB et al. Experiences with high dose radiopeptide therapy: the health physics perspective. Health Physics 199976 225-235.

30 Krenning EP, Kooij PP, Bakker WH, Breeman WA, Postema PT, Kwekkeboom DJ et al. Radiotherapy with a radiolabeled somatostatin analogue, [111In-DTPA-D-Phe1]-octreotide. A case history. Annals of New York Academic Sciences 1994733 496-506.

31 Tiensuu JE, Eriksson B, Oberg K, Skogseid B, Ohrvall U, Nilsson S et al. Treatment with high dose [(111)In-DTPA-D-PHE1]-octreotide in patients with neuroendocrine tumors-evaluation of therapeutic and toxic effects. Acta Oncologica 199938 373-377.

Received 26 May 2003

Accepted 8 September 2003 